\title{
Antithrombocytopenic potential of metabolically characterized extract and fractions of Momordica charantia L. fruits by in vivo study
}

\author{
Adil Ahmad, Mohammad Ibrahim, Shahid Husain Ansari, Mohamad Taleuzzaman* and Sayeed Ahmad* \\ Bioactive Natural Product Laboratory, Department of Pharmacognosy and Phytochemistry, School of Pharmaceutical Education and \\ Research, Jamia Hamdard-110062, New Delhi, India \\ * Department of Pharmaceutical Chemistry, Faculty of Pharmacy, Maulana Azad University, Village Bujhawar, Tehsil Luni, Jodhpur-342802, \\ Rajasthan, India
}

\section{Article Info}

\section{Article history}

Received 20 July 2021

Revised 7 September 2021

Accepted 8 September 2021

Published Online 30 December 2021

\section{Keywords}

Momordica charantia L.

UPLC-MS

Antithrombocytopenic potential

Busulfan

Platelet count

\begin{abstract}
Momordica charantia L. is a popular medicinal plant used in the traditional system of medicine for the management or treatment of various diseases and disorders. This study was aimed to explore the antithrombocytopenic potential of extract and different fractions of $M$. charantia fruits in busulfan-induced thrombocytopenic rats. The hydroalcoholic extract (mother extract) was prepared and further fractionated based on polarity such as n-hexane, dichloromethane (DCM), n-butanol, and aqueous, respectively. Interestingly, the DCM fraction and mother extract were identified as potent antithrombocytopenic agents. DCM fractions and mother extract were metabolically characterized using ultra-performance liquid chromatography-tandem mass spectrometry (UPLC-MS). A total of 08 and 05 metabolites were tentatively identified in the DCM fraction and mother extract, respectively. Moreover, standardized DCM fractions and mother extract of $M$. charantia significantly $(p<0.05)$ enhanced platelet count as compared to other fraction like hexane, n-butanol, and aqueous. Among all, the DCM fraction improves overall tested parameters of the blood including RBC, hemoglobin, and neutrophil. Therefore, observed results inferred that $M$. charantia can be used for the management of thrombocytopenia.
\end{abstract}

\section{Introduction}

Dengue is one of the major evolving viral diseases that threaten human life and economies throughout the globe. In the recent past, occurrence of dengue increases dramatically across the world. Annually, about 390 million people suffering from dengue infections globally that leads to 25,000 deaths. As per the report published by WHO in 2021, the number of dengue cases was reported at 2.2 million in 2010 but in 2019, the number of cases reached 5.2 million (WHO, 2021). Primarily, dengue weakens the body's immunity and the most common associated symptoms were observed such as headache, hypertension, mental disorders, inflammation, liver inflammation, and thrombocytopenia with or without hemorrhage. In case of severe and long-term occurrence of dengue may damage the liver cause excessive bleeding that leads to human death (Ahmad et al., 2019).

Platelets are a type of blood cells produced in the bone marrow that play a key role in the maintenance of hemostasis. It is also involved in blood clotting to prevent blood loss in injury. Thrombocytopenia (low count of platelet/thrombocytes) is associated with prolonged bleeding and clotting time due to deficient platelet counts in the blood and it occurs either by genetic disorders or infections like dengue fever, parvovirus, and bacterial infections like tuberculosis

Corresponding author: Dr. Sayeed Ahmad

Associate Professor, Department of Pharmacognosy and Phytochemistry, School of Pharmaceutical Education and Research, Jamia Hamdard-110019, New Delhi, India

E-mail: sahmad_jh@yahoo.co.in

Tel.: +91-9891374647

Copyright (c) 2021 Ukaaz Publications. All rights reserved.

Email: ukaaz@yahoo.com; Website: www.ukaazpublications.com
(Talla 2015). Most of the anticancer agents cause thrombocytopenia as an adverse effect during the period of treatment. Based on the above effect, busulfan was used to induce thrombocytopenia in experimental animals for the evaluation of platelet augmentation activity of prepared extract and fraction (Zunjar et al., 2016). To date, no vaccine or medicament is available to us for the management of dengue-induced thrombocytopenia, hence people are relies on traditional medicine to cure dengue. For millennia, Momordica charantia is a very important medicinal plant used for the management of various diseases and disorders. This plant belonging to the family Cucurbitaceae and is commonly known as bitter gourd (Habicht et al., 2011). Cited literature revealed that seeds and fruit of M. charantia possess therapeutic effects (Grover and Yadav, 2004; Prasad et al., 2006). It offers a huge number of pharmacological values such asantidiabetic, antimicrobial, hepatoprotective, anticancer and anti-inflammatory activities, and many more (Raman and Lau 1996; Virdi et al., 2003.; Mada et al., 2013; Costa et al., 2010; Jagessara et al., 2008).

M. charantia is a good source of natural antioxidants, has shown its activity against oxidant damage (Fernandes et al., 2007; Lucas et al. 2010; Xie et al., 2010). Leaves and stems ethanol extracts have antiviral effects which inhibit HSV-1 and SINV viruses (Beloin et al., 2005; Lee-Huang et al., 1990). Dar and his team reported that $M$. charantia elevates platelet counts, hemoglobin and also maintains electrolyte balance (Dar et al., 2014). It also possesses antiinflammatory effects by the mechanism which inhibits infiltration of neutrophils and NF- $\mathrm{KB}$ activation, depressed MMP-9 levels, and ameliorates TNF- $\alpha$ IL-8, and IL-1 $\beta$ levels (Huang et al., 2015; Jia et al., 2017). Day-by-day resurgence of herbal preparations increases 
globally but, due to the lack of inadequate regulations, these formulations are not being accepted by the modern world. Therefore, the present study explored to ascertain the antithrombocytopenic effect of $M$. charantia in an experimental animal model of rats along with complete quality control analysis of used extract and fraction. Moreover, the resulting outcome can be used to explore the action mechanism of responsible bioactive metabolites for the management of dengue fever/thrombocytopenic conditions.

\section{Materials and Methods}

\subsection{Plant materials and chemicals}

Fresh fruits of $M$. charantia were collected from the Khari Bawali, New Delhi, India, and taxonomic identification was done at CSIRNISCAIR, New Delhi by Dr. Sunita Garg, Chief Scientist. The sample has been deposited at BNPL, SPER, Jamia Hamdard for future reference (Voucher Specimen No. NISCAIR/RHMD/Consult/2015/ 2889/82-1). Chemicals used in this study were of analytical grade and purchased from SD Fine Chemicals (India). Busulfan was purchased from Sigma-Aldrich (India) and used for induction of thrombocytopenia in rats.

\subsection{Preparation of extract and its fractionation}

$100 \mathrm{gm}$ whole fruits of $M$. charantia were powdered, extracted with $80 \% \mathrm{v} / \mathrm{v}$ ethanol for $16 \mathrm{~h}$ at $80^{\circ} \mathrm{C}$ using soxhlet apparatus. The filtrate was dried on a water bath, further dried extract was suspended in water $(10 \mathrm{~g} / \mathrm{ml})$ for $15 \mathrm{~min}$ at $45^{\circ} \mathrm{C}$. The suspension was obtained, partitioned, and fractionated using $n$-hexane, dichloromethane (DCM), $n$-butanol, and water-based on polarity. The obtained fractions were dried using rota vapor and stored in a well-closed container for further use (Figure 1) (Pisoschi et al., 2016).

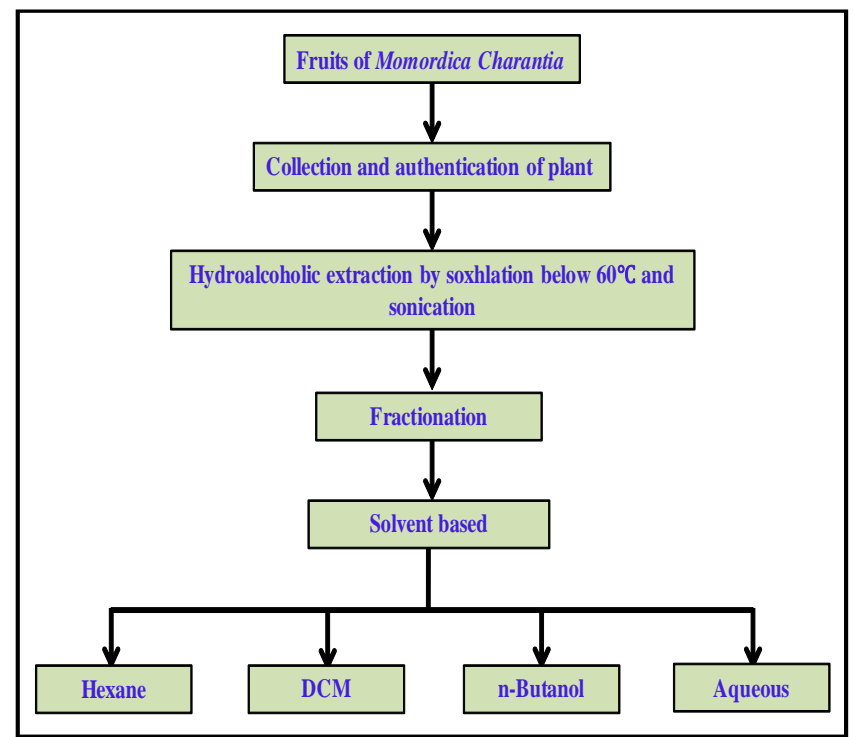

Figure 1: Typical layout for the extraction and their fraction ationusing different solvent system.

\subsection{UPLC-MS analysis}

The samples were prepared in LC-MS grade methanol. Before analysis, the sample was filtered using a syringe filter. Chromatographic separation of metabolites was done using mobile consisting of $0.5 \%$ formic acid in water (A) and acetonitrile (B) and BEH C18
$(100 \mathrm{~mm} \times 2.1 \mathrm{~mm} \times 1.7 \mu \mathrm{m})$ column was used as a stationary phase. The gradient elution mode was used for the separation of metabolites in the samples with a flow rate of $0.4 \mathrm{ml} / \mathrm{min}$. Five microliters filtered sample diluted in methanol was injected, and the maximum bearable pressure of the system was set to 15,000 psi. The separated metabolites were detected by the MS detector. The cone gas and nebulizer gas were set to $50 \mathrm{l} / \mathrm{h}$ and $500 \mathrm{l} / \mathrm{h}$, respectively. The source temperature of the MS was set to $100^{\circ} \mathrm{C}$ while the voltage of the cone and capillary was set to $40 \mathrm{kV}$ and $3.0 \mathrm{kV}$, respectively. On the basis of the analyzed $\mathrm{m} / \mathrm{z}$ value, the separated metabolites were identified (Ibrahim et al., 2021).

\subsection{Effect of extract and fractions on thrombocytopenic rats}

The in vivo preclinical study was used to investigate antithrombocytopenic Wistar rats (150-250 g) according to standard protocol. Animals were obtained from the Central Animal House Facility of Jamia Hamdard. The study protocol was approved (Approval Number: 915) by the Institutional Animal Ethics Committee, constituted by the Committee for Control and Supervision of Experiments on Animals.

Animals were randomly distributed into seven groups $(n=6)$. Group I, served as control; received normal saline. Group II to Group VII received $5.0 \mathrm{mg} / \mathrm{kg}$ busulfan on days $1,5,10$, and 15 . Group II only received $5.0 \mathrm{mg} / \mathrm{kg}$ busulfan and served as toxic control while Group III to Group VII received hydroalcoholic extract $(240 \mathrm{mg} / \mathrm{kg}), n$ hexane fraction $(25 \mathrm{mg} / \mathrm{kg})$, DCM fraction $(31 \mathrm{mg} / \mathrm{kg}), n$-butanol fraction $(58 \mathrm{mg} / \mathrm{kg})$, and aqueous fraction $(82 \mathrm{mg} / \mathrm{kg})$, respectively. The dose of extract and fractions was calculated based on respective extractive values, and it is equivalent to the dose which was $500 \mathrm{mg} /$ $\mathrm{kg} \mathrm{BW}$ of momordica fruits (Ullah et al., 2012).

Based on the screening results, one potent fraction, i.e., DCM and mother extract were identified based on platelet count (PC). Further, blood samples of the bioactive fraction and mother extract were tested for other hematological parameters for antithrombocytopenic activity on the busulfan induced model, and other biochemical parameters such as total leukocyte count (TLC), hemoglobin count, red blood cells (RBCs), neutrophil count, packed cell volume/ hematocrit (PCV/HCT), mean corpuscular volume (MCV), mean corpuscular hemoglobin $(\mathrm{MCH})$, and $\mathrm{MCH}$ concentration (MCHC) were also analyzed.

The day before the start of the experiment, the PC was analyzed in all the rats. Further, platelets were counted in the experimental and busulfan treated groups on days 5, 10, 15, and 20 in an automated hematology analyzer. Blood samples were collected from the retroorbital vein of an animal by ethylene diaminetetra acetic acid (EDTA) coated capillary tube and stored in EDTA tube after $1 \mathrm{~h}$ of dose administration. After $1 \mathrm{~h}$ of dosing, we have collected blood samples at the scheduled time to maintain uniformity. The collected blood samples were subjected to analysis of PC, total leukocyte count, hemoglobin count, RBC, neutrophil count, PCV/HCT, MCV, MCH, and MCHC (Wada et al., 2015).

\subsection{Platelet function analysis}

- Hematology

- Bleeding time (BT)

- Clotting time (CT) 
Blood samples were collected on Day 0 and Day 7 for hematology and BT, CT). The sample was analyzed using an autoanalyzer for the following hematological parameters: platelet count (PC), total leukocyte count (TLC), bleeding time (BT), and clotting time (CT) (Lee and Lee, 2018) on days $0,5,10,15$ and day $20^{\text {th }}$ of the experiment for selection of most active fraction.

\subsection{Statistical analysis}

All the experiments were performed in triplicate $(n=3)$, and data have been expressed as mean with standard error of mean. Tukey's test was performed for the evaluation of statistical significance analysis. $\mathrm{P}$ values were expressed by comparing all datasets with each other at $95 \%$ confidence intervals (Kickler et al., 2009).

\subsection{Platelet function analysis}

The PC was estimated from citrated plasma using standard kit Erbaactime and Erbaprotime made especially for CA 50 Coagulation Analyzer, Transasia (Sysmex Corporation Kobe, Japan) on days 0, $5,10,15$, and day $20^{\text {th }}$ (Dhurat and Sukesh, 2014).

\section{Results}

\subsection{Preparation of extract and fractions}

500 grams of whole fruits was extracted using ethanol $80 \% \mathrm{v} / \mathrm{v}$ and percentage yield was obtained, i.e., $27.1 \% \mathrm{w} / \mathrm{w}$. Further, these extracts were fractioned using $n$-hexane, DCM, $n$-butanol, and water, respectively. Percentage yields of the fractions were recorded such as $3.34 \%, 4.26 \%, 7.9 \%$, and $11.11 \%$, for $n$-hexane, DCM, n-butanol, and aqueous. During fractionation, $2.5 \mathrm{~g}$ of hydroalcoholic extract was lost (Figure 2).

3.2 Ultra-performance liquid chromatography-mass spectrometry analysis of extract and fraction

Results of UPLC-MS analysis revealed good separation of metabolites and these metabolites were identified using experimental $\mathrm{m} / \mathrm{z}$ values from mass bank and literature survey. Identified metabolites, retention times, $\mathrm{m} / \mathrm{z}$, and name of metabolites was summarized in Table 2.

A total of 13 metabolites were identified in the DCM fraction and extract. Out of which, three metabolites were common such as kaempferol-3-O-arabinoside, phthalamic acid, and 2-coumaric acid. There are 07 and 05 metabolites were found in the DCM fraction and mother extract, respectively. The chromatographic analysis is one of the important parameters to establish the quality of products. It is also used to reduce fraudulence in quality control analysis. Hence, these chromatographic techniques seem to be ideal for the generation of scientific data in the quality control of herbal products or botanicals. Analyzed metabolites were identified by comparing the mass with the data present in the literature (Table 1).

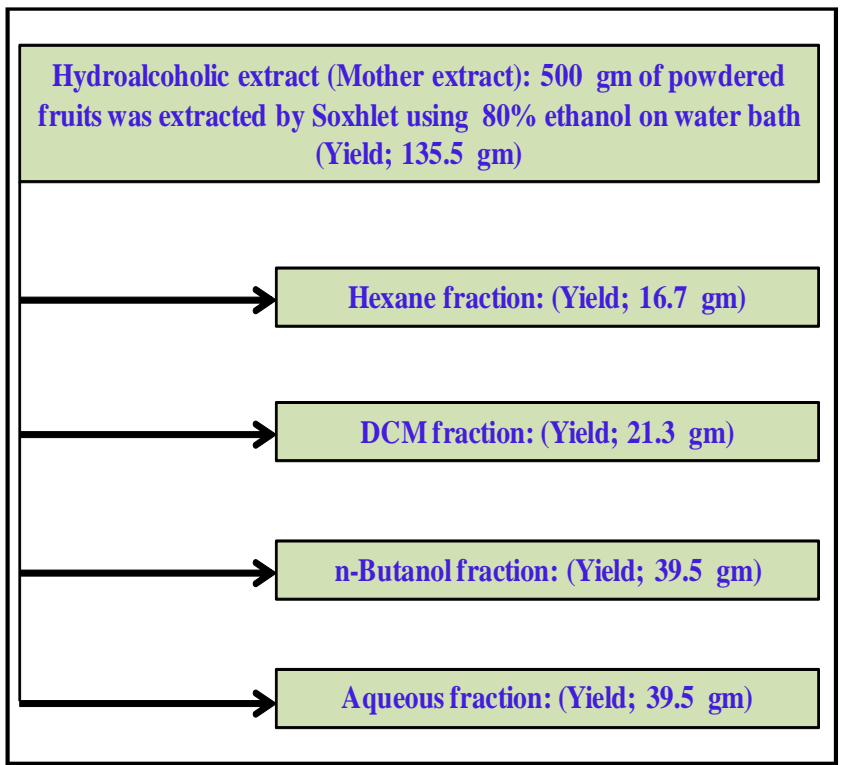

Figure 2: Yield of mother extract and their fraction.

Table 1: Different metabolites in DCM fraction and mother extract analyzed by UPLC-MS

\begin{tabular}{|c|c|r|l|c|c|}
\hline S. No. & $\mathbf{R}_{\mathbf{t}}(\mathbf{m i n})$ & $\boldsymbol{m} / \boldsymbol{z}$ & Metabolite name & DCM fraction & Mother extract \\
\hline 1 & 0.21 & 495.34 & Malvidin-3-O-glucoside & + & - \\
2 & 0.22 & 273.05 & Phloretin & + & + \\
3 & 0.23 & 419.33 & Kaempferol-3-O-arabinoside & + & + \\
4 & 0.28 & 413.267 & Solasodin & + & - \\
5 & 0.32 & 437.34 & Phloretin-2'-O-glucoside & + & - \\
6 & 0.35 & 205.189 & Alpha-lipoic acid & - & + \\
7 & 0.52 & 118.086 & Alpha-hydroxyisovaleric acid & + & + \\
8 & 0.94 & 293.20 & (+)-Cinchonine & + \\
9 & 0.94 & 161.011 & 4-Hydroxycoumarin & + \\
10 & 1.00 & 165.0485 & Phthalamic acid & + \\
11 & 2.00 & 166.0512 & Alpha-hydroxyhydrocinnamic acid & + & + \\
12 & 4.65 & 165.0485 & 2-Coumaric acid & + \\
13 & 7.74 & 104.1018 & Choline & + \\
\hline
\end{tabular}


3.3 The antithrombocytopenic activity of hydroalcoholic extract and its fractions

Hydroalcoholic extract and prepared fractions were administered to busulfan-treated rats. Observed results revealed that the DCM fraction and mother extract were showed better antithrombocytopenic activity as compared to other groups (Figure 3). Based on the preliminary observed results, we have considered DCM fraction and mother extract and their sham control for further evaluation of antithrombocytopenic potential and chromatographic analysis.

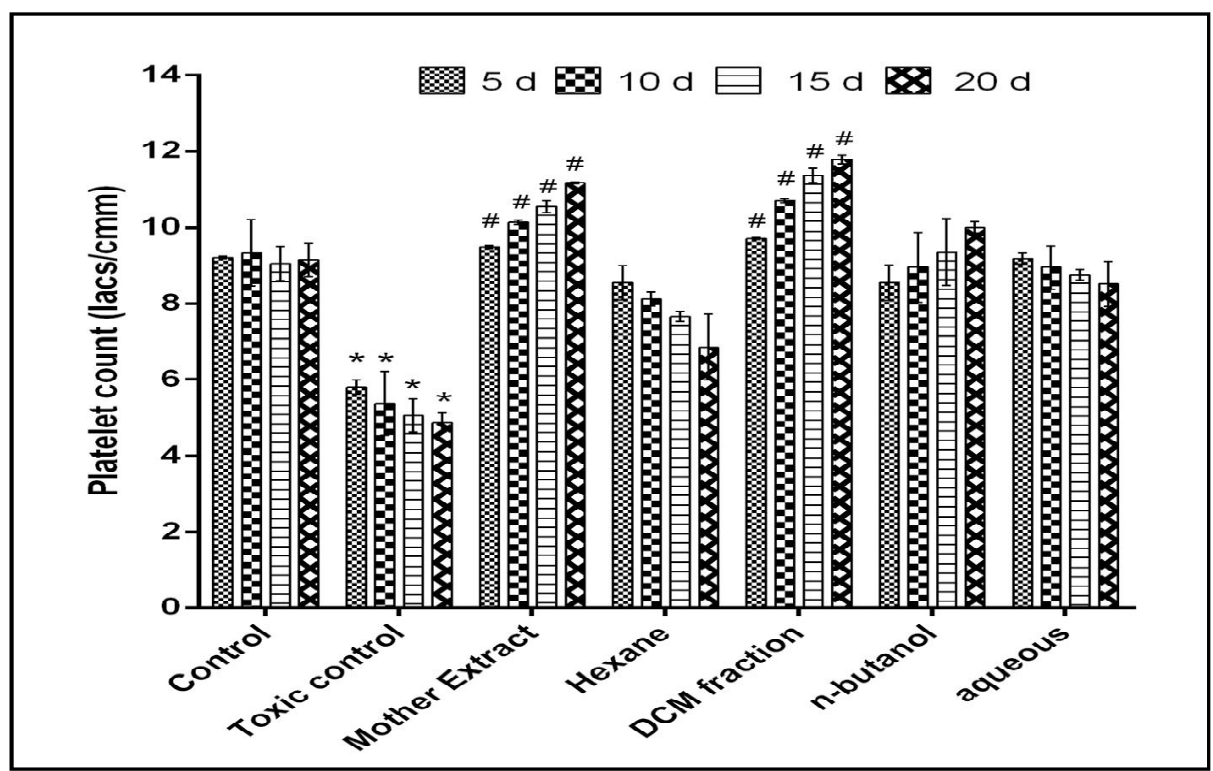

Figure 3: Effect of hydroalcoholic extract and their fraction on platelet count. Data were expressed as mean with relative standard error of mean. Significant analysis was performed with a comparison of toxic control for all days except day 5 .

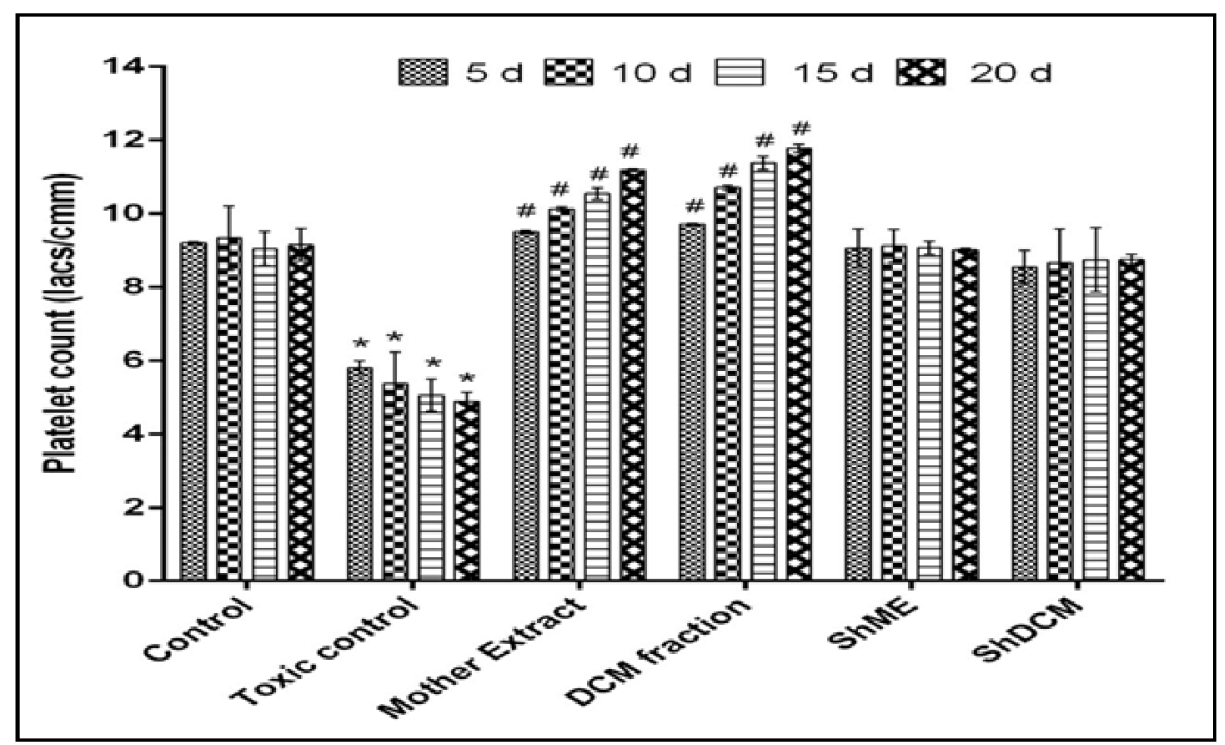

Figure 4: Effect of mother extract and their dichloromethane fraction on platelet count. Data were expressed as mean with relative standard error of mean. Significant analysis was performed with a comparison of toxic control for all days except day 5.

\subsection{Platelet count}

The busulfan-induced experimental model of thrombocytopenia was confirmed by the reduction of PC. After administration of busulfan to experimental rats, the level of PC was significantly decreased $(p<0.05)$. Conversely, after intake of extract, the PC restore to normal as compared to an untreated rat. While $M$. charantia mother extract and DCM fraction and their respective sham control did not show any significant $(p<0.05)$ change in PC as like toxic control. Contemporary, mother extract and DCM fraction treatment groups significantly $(p<0.05)$ reverse the level of platelets as compared to toxic control. This effect is attributable to improved platelet redistribution from the spleen (Colli et al., 2017). Among the mentioned two preparations, the DCM fraction was found to be more significant (Figure 4). 


\subsection{Total leukocyte count and lymphocyte count}

Total leukocyte counts significantly decreased $(p<0.05)$ in the toxic group $(24.2 \%)$ as compared to the normal group. The percentage of total leukocytes in the normal and sham control groups was found significantly higher $(p<0.05)$ as compared to the treatment group.
However, within 20 days of treatment with DCM fraction and mother extract, leukocyte count was significantly $(p<0.05)$ ameliorated. $M$. charantia causes no significant change $(p<0.05)$ in the percentage of lymphocyte count against busulfan-treated animals. Even the sham control groups for DCM fraction and mother extract did not produce any significant change (Table 2).

Table 2: Effect of DCM fraction, mother extract and their respective sham groups of $M$. charantia on total leukocyte count and lymphocyte count

\begin{tabular}{|c|l|c|c|c|c|c|c|}
\hline Day & Parameters & $\begin{array}{c}\text { Normal } \\
\text { control }\end{array}$ & $\begin{array}{c}\text { Toxic } \\
\text { control }\end{array}$ & $\begin{array}{c}\text { Mother } \\
\text { extract }\end{array}$ & $\begin{array}{c}\text { DCM } \\
\text { fraction }\end{array}$ & $\begin{array}{c}\text { Sham mother } \\
\text { extract }\end{array}$ & $\begin{array}{c}\text { Sham DCM } \\
\text { extract }\end{array}$ \\
\hline \multirow{2}{*}{5} & Leukocyte $($ per $\mu \mathrm{l})$ & $10555 \pm 18.9^{* *}$ & $8000 \pm 10.2$ & $7300 \pm 12.6^{* *}$ & $9500 \pm 23.9^{* *}$ & $10800 \pm 4.4^{* *}$ & $10500 \pm 3.7^{* *}$ \\
\cline { 2 - 7 } & Lymphocyte & $87.5 \pm 0.7^{*}$ & $84.0 \pm 1.5$ & $81.5 \pm 5.6^{* *}$ & $83.5 \pm 1.6^{\mathrm{ns}}$ & $80.0 \pm 2.8^{*}$ & $83.5 \pm 4.6^{\mathrm{ns}}$ \\
\hline \multirow{2}{*}{$\mathbf{0}$} & Leukocyte $($ per $\mu \mathrm{l})$ & $10405 \pm 16.0^{* *}$ & $5950 \pm 10.1$ & $5450 \pm 40.2^{* *}$ & $7950 \pm 15.4^{* *}$ & $10400 \pm 3.4^{* *}$ & $10100 \pm 3.1^{* *}$ \\
\cline { 2 - 7 } & Lymphocyte & $86.5 \pm 1.0^{\mathrm{ns}}$ & $81.5 \pm 2.4$ & $85.0 \pm 2.8^{\mathrm{ns}}$ & $86.5 \pm 0.8^{\mathrm{ns}}$ & $82.5 \pm 2.7^{* *}$ & $81.5 \pm 4.7^{\mathrm{ns}}$ \\
\hline \multirow{2}{*}{$\mathbf{1 5}$} & Leukocyte $($ per $\mu \mathrm{l})$ & $10142 \pm 18.9^{* *}$ & $3900 \pm 10.4$ & $5350 \pm 8.4^{* *}$ & $7250 \pm 26.8^{* *}$ & $9900 \pm 3.1^{* *}$ & $11300 \pm 3.9^{* *}$ \\
\cline { 2 - 8 } & Lymphocyte & $86.0 \pm 1.0^{\mathrm{ns}}$ & $79.0 \pm 1.7$ & $79.5 \pm 0.7^{\mathrm{ns}}$ & $84.0 \pm 0.0^{*}$ & $83.0 \pm 2.9^{* *}$ & $79.5 \pm 4.1^{\mathrm{ns}}$ \\
\hline \multirow{2}{*}{$\mathbf{0}$} & Leukocyte $($ per $\mu \mathrm{l})$ & $10400 \pm 12.1^{* *}$ & $2800 \pm 2.3$ & $8250 \pm 20.2^{* *}$ & $9200 \pm 41.8^{* *}$ & $9300 \pm 4.3^{* *}$ & $11000 \pm 3.8^{* * *}$ \\
\cline { 2 - 8 } & Lymphocyte & $87.5 \pm 1.4^{\mathrm{ns}}$ & $87.5 \pm 1.6$ & $83.5 \pm 2.1^{\mathrm{ns}}$ & $85.5 \pm 4.8^{\mathrm{ns}}$ & $80.0 \pm 2.6^{* *}$ & $76.5 \pm 4.0^{* *}$ \\
\hline
\end{tabular}

Data are expressed as mean \pm SEM $(n=6)$. Values with superscripts $\left(^{*}\right)$ is significantly different between toxic control vs treatment groups. The value $p<0.05$ considered significant. The symbol represents the significance level such as $* p<0.05 ; * * p<0.01$ and $* * * p<0.001)$ and superscripts ${ }^{(\mathrm{ns})}$ represents not significant.

Table 3: Effect of DCM fraction, mother extract and their respective sham groups of $M$. charantia on hemoglobin content, red blood cell, and neutrophil count

\begin{tabular}{|c|c|c|c|c|c|c|c|}
\hline Day & Parameters & $\begin{array}{l}\text { Normal } \\
\text { control }\end{array}$ & $\begin{array}{c}\text { Toxic } \\
\text { control }\end{array}$ & $\begin{array}{l}\text { Mother } \\
\text { extract }\end{array}$ & $\begin{array}{c}\text { DCM } \\
\text { fraction }\end{array}$ & $\begin{array}{c}\text { Sham mother } \\
\text { extract }\end{array}$ & $\begin{array}{c}\text { Sham DCM } \\
\text { extract }\end{array}$ \\
\hline \multirow[t]{3}{*}{5} & $\mathrm{RBC}\left(\right.$ Millions $/ \mathrm{mm}^{3}$ ) & $8.7 \pm 0.1^{* *}$ & $7.3 \pm 0.1$ & $7.8 \pm 0.2^{\mathrm{ns}}$ & $8.0 \pm 0.2^{\mathrm{ns}}$ & $8.1 \pm 0.1^{* *}$ & $8.86 \pm 0.2^{* *}$ \\
\hline & Hemoglobin (g/dl) & $15.8 \pm 0.3^{* *}$ & $13.1 \pm 0.5$ & $13.2 \pm 0.4^{\mathrm{ns}}$ & $13.0 \pm 0.1^{\mathrm{ns}}$ & $14.1 \pm 0.4^{*}$ & $13.0 \pm 0.1^{\mathrm{ns}}$ \\
\hline & Neutrophil (\%) & $16.5 \pm 1.1^{* *}$ & $13.0 \pm 0.6$ & $16.6 \pm 0.5^{* *}$ & $14.7 \pm 0.1^{* *}$ & $14.3 \pm 0.4^{* *}$ & $13.0 \pm 0.1^{* *}$ \\
\hline \multirow[t]{3}{*}{10} & $\mathrm{RBC}\left(\right.$ Millions $/ \mathrm{mm}^{3}$ ) & $8.2 \pm 0.1^{\mathrm{ns}}$ & $7.2 \pm 1.1$ & $6.7 \pm 0.1^{\mathrm{ns}}$ & $7.8 \pm 0.8^{\mathrm{ns}}$ & $8.3 \pm 0.1^{* *}$ & $7.35 \pm 0.4^{\mathrm{ns}}$ \\
\hline & Hemoglobin $(\mathrm{g} / \mathrm{dl})$ & $15.6 \pm 0.3^{* * *}$ & $12.9 \pm 1.4$ & $12.0 \pm 0.6^{\mathrm{ns}}$ & $12.2 \pm 0.9^{\mathrm{ns}}$ & $13.5 \pm 0.4^{\mathrm{ns}}$ & $12.1 \pm 0.6^{\mathrm{ns}}$ \\
\hline & Neutrophil (\%) & $16.1 \pm 0.3^{* *}$ & $13.5 \pm 1.4$ & $13.5 \pm 0.6^{* *}$ & $13.9 \pm 0.9^{\mathrm{ns}}$ & $13.6 \pm 0.4^{\mathrm{ns}}$ & $12.1 \pm 0.6^{\mathrm{ns}}$ \\
\hline \multirow[t]{3}{*}{15} & $\mathrm{RBC}\left(\right.$ Millions/mm $\left.{ }^{3}\right)$ & $8.8 \pm 0.1^{\mathrm{ns}}$ & $7.1 \pm 1.6$ & $6.2 \pm 1.1^{\mathrm{ns}}$ & $7.5 \pm 0.4^{\mathrm{ns}}$ & $8.8 \pm 1.1=$ & $8.23 \pm 0.2^{\mathrm{ns}}$ \\
\hline & Hemoglobin $(\mathrm{g} / \mathrm{dl})$ & $16.2 \pm 0.2^{* *}$ & $11.8 \pm 1.1$ & $13.1 \pm 0.3^{\mathrm{ns}}$ & $13.3 \pm 2.2^{\mathrm{ns}}$ & $14.2 \pm 1.6^{\mathrm{ns}}$ & $13.1 \pm 1.1^{* *}$ \\
\hline & Neutrophil (\%) & $15.5 \pm 0.3^{\mathrm{ns}}$ & $13.0 \pm 1.1$ & $16.0 \pm 0.40^{* *}$ & $13.1 \pm 2.3^{\mathrm{ns}}$ & $14.1 \pm 1.7^{\mathrm{ns}}$ & $13.2 \pm 1.1^{\mathrm{ns}}$ \\
\hline \multirow[t]{3}{*}{20} & RBC(Millions/mm m $\left.^{3}\right)$ & $8.5 \pm 0.2^{* *}$ & $5.9 \pm 0.4$ & $6.0 \pm 1.1^{\mathrm{ns}}$ & $6.5 \pm 1.2^{*}$ & $8.5 \pm 0.1^{* *}$ & $7.92 \pm 0.2^{* *}$ \\
\hline & Hemoglobin $(\mathrm{g} / \mathrm{dl})$ & $15.9 \pm 0.4^{* * *}$ & $9.7 \pm 0.7$ & $11.9 \pm 0.9^{*}$ & $12.9 \pm 2.8^{* *}$ & $16.3 \pm 0.5^{* *}$ & $15.6 \pm 1.1^{* *}$ \\
\hline & Neutrophil (\%) & $15.5 \pm 1.1^{*}$ & $11.9 \pm 0.8$ & $14.9 \pm 0.9^{* *}$ & $12.7 \pm 2.8^{\mathrm{ns}}$ & $16.3 \pm 0.5^{* *}$ & $15.8 \pm 1.1^{* *}$ \\
\hline
\end{tabular}

Data are expressed as mean \pm SEM $(\mathrm{n}=6)$. Values with superscripts $(*)$ is significantly different between toxic control vs treatment groups. The value $p<0.05$ considered significant. The symbol represents the significance level such as $* p<0.05 ; * * p<0.01$ and $* * * p<0.001)$ and superscripts ${ }^{(\text {ns })}$ represents not significant. 
3.6 Hemoglobin content, red blood cell, and neutrophil count

The rats were treated with busulfan, crude extracts of $M$. charantia, and its fractions for 20 days. On the day of $0,5,10,15$, and 20, blood was collected from different groups of rats. It has been observed that hemoglobin was significantly decreased $(p<0.01)$ in toxic control as compared to normal control $(25.17 \%)$. There was no significant difference $(p>0.05)$ observed between the normal control and sham groups. DCM fraction and mother extract of $M$. charantia showed a better effect and increase the hemoglobin against toxic control (Table 3). In the case of RBC, little change was observed in the busulfan treated groups as compared to the normal control group. On the other hand, there were no significant changes found between the normal control and sham groups (Table 3). Similar results were also observed in the case of neutrophil count. It has been observed that neutrophil count was little significantly decreased $(p<0.01)$ in toxic control as compared to normal control $(19.18 \%)$. There was no significant difference $(p>0.05)$ observed between the normal control and sham groups.

\subsection{Packed cell volume (PCV)}

At the end of the treatment period, HCT level was significantly decreased $(p<0.01)$ in busulfan treated rats when compared to normal control; contemporarily, there was no significant difference shown between the normal control and sham groups. Busulfan caused a decrease in PCV which was reversed in rats treated with DCM fraction and mother extract of $M$. charantia. Decreased hematocrit level generally causes anemia in humans and most animals. The present study revealed that the DCM fraction of hydroalcoholic extract was identified as a bioactive fraction that restores hematocrit level close to the normal range against toxic control (Table 4).

Table 4: Effect of DCM fraction, mother extract and their respective sham groups of $M$. charantia on packed cell volume (PCV)

\begin{tabular}{|c|c|c|c|c|c|c|c|}
\hline Day & Parameters & $\begin{array}{l}\text { Normal } \\
\text { control }\end{array}$ & $\begin{array}{c}\text { Toxic } \\
\text { control }\end{array}$ & $\begin{array}{l}\text { Mother } \\
\text { extract }\end{array}$ & $\begin{array}{c}\text { DCM } \\
\text { fraction }\end{array}$ & $\begin{array}{c}\text { Sham mother } \\
\text { extract }\end{array}$ & $\begin{array}{c}\text { Sham DCM } \\
\text { extract }\end{array}$ \\
\hline \multirow[t]{4}{*}{5} & $\mathrm{MCH}(p g)$ & $33.5 \pm 0.0^{\mathrm{ns}}$ & $28.0 \pm 1.4$ & $37.0 \pm 0.7^{\mathrm{ns}}$ & $28.0 \pm 0.7^{\mathrm{ns}}$ & $31.5 \pm 0.7^{\mathrm{ns}}$ & $30.0 \pm 0.7^{\mathrm{ns}}$ \\
\hline & $\mathrm{MCHC}(\mathrm{g} / \mathrm{dl})$ & $45.0 \pm 0.3^{\mathrm{ns}}$ & $41.5 \pm 0.7$ & $41.5 \pm 0.0^{\mathrm{ns}}$ & $41.0 \pm 2.1^{\mathrm{ns}}$ & $42.5 \pm 0.7^{\mathrm{ns}}$ & $43.0 \pm 0.7^{\mathrm{ns}}$ \\
\hline & $\operatorname{MCV}(f l)$ & $76.0 \pm 0.3^{* * *}$ & $67.5 \pm 2.1 \mathrm{~ns}$ & $68.5 \pm 2.8^{\mathrm{ns}}$ & $67.5 \pm 2.8^{\mathrm{ns}}$ & $72.0 \pm 0.0 \mathrm{~ns}^{* *}$ & $74.0 \pm 1.1^{* *}$ \\
\hline & PCV (\%) & $59.5 \pm 1.4^{* *}$ & $47.5 \pm 0.7$ & $48.5 \pm 0.0^{\mathrm{ns}}$ & $48.0 \pm 0.7^{\mathrm{ns}}$ & $61.5 \pm 2.1^{* *}$ & $59.0 \pm 0.7^{* *}$ \\
\hline \multirow[t]{4}{*}{10} & MCH (pg) & $36.0 \pm 0.3^{* * *}$ & $27.0 \pm 0.0$ & $28.5 \pm 1.4^{\mathrm{ns}}$ & $28.0 \pm 0.7^{\mathrm{ns}}$ & $32.0 \pm 1.4^{* * *}$ & $32.5 \pm 0.6^{* *}$ \\
\hline & $\mathrm{MCHC}(\mathrm{g} / \mathrm{dl})$ & $46.5 \pm 0.7^{* *}$ & $40.0 \pm 0.0$ & $41.0 \pm 0.7^{\mathrm{ns}}$ & $41.5 \pm 0.0^{\mathrm{ns}}$ & $43.0 \pm 1.6^{\mathrm{ns}}$ & $42.6 \pm 0.8^{\mathrm{ns}}$ \\
\hline & MCV (fl) & $77.0 \pm 0.3^{* * *}$ & $68.5 \pm 0.7$ & $69.5 \pm 2.8^{\mathrm{ns}}$ & $66.5 \pm 1.4^{*}$ & $76.0 \pm 0.8^{* * *}$ & $55.0 \pm 0.3^{* *}$ \\
\hline & PCV (\%) & $59.5 \pm 0.7^{* * *}$ & $46.5 \pm 4.9$ & $46.5 \pm 1.4^{\mathrm{ns}}$ & $47.5 \pm 2.8^{\mathrm{ns}}$ & $59.0 \pm 2.1^{* * *}$ & $56.6 \pm 1.7^{* *}$ \\
\hline \multirow[t]{4}{*}{15} & $\mathrm{MCH}(\mathrm{pg})$ & $36.5 \pm 0.720^{* *}$ & $28.0 \pm 1.4$ & $28.5 \pm 2.8^{\mathrm{ns}}$ & $28.0 \pm 2.1^{\mathrm{ns}}$ & $30.5 \pm 2.1^{\mathrm{ns}}$ & $31.4 \pm 0.7^{\mathrm{ns}}$ \\
\hline & $\mathrm{MCHC}(\mathrm{g} / \mathrm{dl})$ & $47.5 \pm 0.7^{* * *}$ & $39.5 \pm 0.7$ & $40.0 \pm 0.7^{\mathrm{ns}}$ & $40.0 \pm 2.8^{\mathrm{ns}}$ & $41.0 \pm 1.0^{\mathrm{ns}}$ & $41.2 \pm 0.9^{\mathrm{ns}}$ \\
\hline & $\operatorname{MCV}(f l)$ & $78.5 \pm 0.7^{\mathrm{ns}}$ & $70.5 \pm 4.9$ & $72.0 \pm 7.7^{\mathrm{ns}}$ & $69.0 \pm 0.7^{\mathrm{ns}}$ & $73.5 \pm 0.6^{\mathrm{ns}}$ & $77.8 \pm 0.7^{\mathrm{ns}}$ \\
\hline & PCV (\%) & $61.5 \pm 0.7^{\text {** }}$ & $45.5 \pm 2.1$ & $48.0 \pm 0.7^{\mathrm{ns}}$ & $48.0 \pm 3.5^{\mathrm{ns}}$ & $58.5 \pm 1.8^{* *}$ & $55.1 \pm 1.7^{* *}$ \\
\hline \multirow[t]{4}{*}{20} & MCH (pg) & $37.0 \pm 0.3^{* *}$ & $27.0 \pm 0.0$ & $29.5 \pm 1.4^{* *}$ & $27.5 \pm 1.4^{\mathrm{ns}}$ & $35.5 \pm 1.3^{* *}$ & $30.5 \pm 0.8^{\mathrm{ns}}$ \\
\hline & $\mathrm{MCHC}(\mathrm{g} / \mathrm{dl})$ & $47.5 \pm 1.4^{* *}$ & $38.0 \pm 1.4$ & $41.5 \pm 0.0^{* *}$ & $40.0 \pm 0.7^{* *}$ & $39.0 \pm 0.9^{\mathrm{ns}}$ & $44.8 \pm 0.6^{* *}$ \\
\hline & MCV (fl) & $77.5 \pm 0.7^{\mathrm{ns}}$ & $72.5 \pm 3.5$ & $74.0 \pm 4.9^{\mathrm{ns}}$ & $67.0 \pm 3.5^{* *}$ & $75.5 \pm 0.7^{\mathrm{ns}}$ & $78.5 \pm 1.4^{\mathrm{ns}}$ \\
\hline & $\mathrm{PCV}(\%)$ & $57.5 \pm 0.7^{* *}$ & $42.5 \pm 0.7$ & $47.5 \pm 4.2^{\mathrm{ns}}$ & $47.0 \pm 7.7^{\mathrm{ns}}$ & $57.0 \pm 1.9^{* * *}$ & $57.2 \pm 1.6^{* *}$ \\
\hline
\end{tabular}

Data are expressed as mean \pm SEM $(\mathrm{n}=6)$. Values with superscripts $(*)$ is significantly different between toxic control vs treatment groups. The value $p<0.05$ considered significant. The symbol represents the significance level such as $* p<0.05 ; * * p<0.01$ and $* * * p<0.001)$ and superscripts $\left({ }^{\text {ns }}\right.$ ) represents not significant.

\subsection{Mean corpuscular volume (MCV)}

$\mathrm{MCV}$ is directly related to $\mathrm{RBC}$ and increases or decreases following the average red cell size. This study revealed that MCV significantly decreased $(p<0.01)$ in toxic control as compared to normal control. Our most intriguing findings are revealed that bioactivity-guided fractions from the hydroalcoholic extract. Table 4 clearly shows the percentage changes in MCV among all the groups. DCM fraction and mother extract showed better results as compared to other fractions. Further, this result showed the ameliorative potential of $M$. charantia to normalize the number of MCV.

\subsection{Mean corpuscular hemoglobin $(\mathrm{MCH})$}

The value of $\mathrm{MCH}$ depletion and elevation were analyzed in all the experimental groups. The MCH levels were not affected in the toxic group and were found almost similar to the normal control group. Interestingly, there was no significant difference $(p>0.05)$ was observed between the normal control group and sham groups. However, M. charantia DCM fraction and mother extract possessed quite similar effects against toxic control (Table 4). 
3.10 Mean corpuscular hemoglobin concentration (MCHC)

The value of MCHC depletion and MCHC elevation were investigated in different experimental groups. No significant changes $(p>0.05)$ in MCHC were observed in busulfan-treated rats as compared to normal control rats. Contemporarily, there were no significant changes found between the normal control and sham groups; hence, it was clear that $M$. charantia does not produce any toxicity. $M$. charantia DCM fraction and mother extract possessed almost similar ameliorative.The observed results are presentedin Table 4.

\subsection{Platelet function analysis}

Effect of $M$. charantia, bioactive guided fractions, and metabolite enriched fractions on BT and CT in albino Wistar rat was found significant. Preliminary screening data were presented in Table 5 while final observation was presented in Tables 6 and 7 for CT and $\mathrm{BT}$, respectively.

Table 5: Effect of DCM fraction, mother extract and their respective sham groups of $M$. charantia on bleeding (BT) and clotting time (CT)

\begin{tabular}{|c|c|c|c|c|}
\hline Groups & \multicolumn{2}{|c|}{ Bleeding time $(s)($ Mean \pm SEM $)$} & \multicolumn{2}{|c|}{ Clotting time $(s)($ Mean \pm SEM $)$} \\
\hline & o Day & 7 Day & 0 Day & 7 Day \\
\hline Normal control & $00.216 \pm 6.52$ & $237.16 \pm 5.87$ & $165.25 \pm 4.25$ & $172.23 \pm 4.29$ \\
\hline Mother extract & $206.83 \pm 5.59^{\mathrm{ns}}$ & $305.66 \pm 6.21$ ns & $165.03 \pm 4.89^{\mathrm{ns}}$ & $190.14 \pm 6.32^{\mathrm{ns}}$ \\
\hline Hexane fraction & $280.50 \pm 11.61^{\mathrm{ns}}$ & $278.50 \pm 11.18^{\mathrm{ns}}$ & $170.33 \pm 04.61^{\mathrm{ns}}$ & $172.66 \pm 05.20^{\mathrm{ns}}$ \\
\hline DCM fraction & $252.00 \pm 6.11^{\mathrm{ns}}$ & $310.00 \pm 6.99$ ns & $157.45 \pm 5.32$ ns & $175.87 \pm 5.78^{\text {ns }}$ \\
\hline$n$-butanol & $261.00 \pm 10.54$ ns & $235.00 \pm 9.2 \mathrm{~ns}$ & $213.05 \pm 7.4^{\mathrm{ns}}$ & $196.05 \pm 5.68^{\mathrm{ns}}$ \\
\hline Aqueous fraction & $261.00 \pm 9.5^{\mathrm{ns}}$ & $243.00 \pm 8.21$ ns & $162.00 \pm 5.90^{\mathrm{ns}}$ & $191.83 \pm 6.2^{\mathrm{ns}}$ \\
\hline
\end{tabular}

Table 6: Effect of DCM fraction, mother extract and their respective sham groups of $M$. charantia on clotting time (CT)

\begin{tabular}{|c|c|c|c|c|c|}
\hline \multirow[t]{2}{*}{ Groups } & \multicolumn{5}{|c|}{ Clotting time $(s)($ Mean \pm SEM $)$} \\
\hline & Day 0 & Day 5 & Day 10 & Day 15 & Day 20 \\
\hline Normal control & $165.25 \pm 4.25^{\mathrm{ns}}$ & $172.23 \pm 4.29^{* *}$ & $170.30 \pm 3.17^{* *}$ & $168.16 \pm 5.12 \mathrm{~ns}$ & $162.83 \pm 4.87^{\mathrm{ns}}$ \\
\hline Toxic control & $166.85 \pm 5.68$ & $211.34 \pm 6.54$ & $198.56 \pm 7.25$ & $177.66 \pm 5.45$ & $165.50 \pm 4.56$ \\
\hline Mother extract & $165.03 \pm 4.89 \mathrm{~ns}$ & $219.14 \pm 6.32 \mathrm{~ns}$ & $201.02 \pm 8.54^{\mathrm{ns}}$ & $185.05 \pm 5.99 \mathrm{~ns}$ & $157.00 \pm 5.87^{\mathrm{ns}}$ \\
\hline DCM extract & $163.54 \pm 6.11^{\mathrm{ns}}$ & $187.45 \pm 4.58^{*}$ & $178.54 \pm 5.54^{*}$ & $161.33 \pm 4.75^{\mathrm{ns}}$ & $148.33 \pm 4.85^{*}$ \\
\hline Sham mother extract & $168.25 \pm 5.55^{\mathrm{ns}}$ & $185.47 \pm 4.67^{*}$ & $164.31 \pm 5.19^{*}$ & $153.05 \pm 4.23^{* *}$ & $149.16 \pm 5.21^{*}$ \\
\hline Sham DCM extract & $157.45 \pm 5.32 \mathrm{~ns}$ & $199.87 \pm 5.78^{\mathrm{ns}}$ & $191.26 \pm 8.37^{\mathrm{ns}}$ & $181.05 \pm 4.86^{\mathrm{ns}}$ & $149.66 \pm 4.23^{*}$ \\
\hline
\end{tabular}

Table 7: Effect of DCM fraction, mother extract and their respective sham groups of $M$. charantia on bleeding time (BT)

\begin{tabular}{|c|c|c|c|c|c|}
\hline \multirow[t]{2}{*}{ Groups } & \multicolumn{5}{|c|}{ Bleeding time (s) (Mean \pm SEM) } \\
\hline & Day 0 & Day 5 & Day 10 & Day 15 & Day 20 \\
\hline Normal control & $216.00 \pm 6.52^{\mathrm{ns}}$ & $237.16 \pm 5.87^{*}$ & $221.50 \pm 6.25^{*}$ & $234.33 \pm 6.58^{\mathrm{ns}}$ & $239.5 \pm 7.25^{\mathrm{ns}}$ \\
\hline Toxic control & $227.83 \pm 5.45^{\mathrm{ns}}$ & $295.56 \pm 5.48$ & $281.15 \pm 6.25$ & $270.00 \pm 6.77$ & $242.16 \pm 6.45$ \\
\hline Mother extract & $206.83 \pm 5.59^{\mathrm{ns}}$ & $305.66 \pm 6.21 \mathrm{~ns}$ & $285.54 \pm 7.80^{\mathrm{ns}}$ & $244.00 \pm 5.46^{\mathrm{ns}}$ & $216.33 \pm 7.41 \mathrm{~ns}$ \\
\hline DCM extract & $246.83 \pm 6.32$ ns & $281.16 \pm 6.32 \mathrm{~ns}$ & $263.43 \pm 7.24$ ns & $255.16 \pm 6.32 \mathrm{~ns}$ & $228.8 \pm 5.41^{\mathrm{ns}}$ \\
\hline Sham Mother extract & $261.83 \pm 6.47^{\mathrm{ns}}$ & $303.66 \pm 7.47$ ns & $273.89 \pm 8.23{ }^{\mathrm{ns}}$ & $229.83 \pm 4.38^{\mathrm{ns}}$ & $214 \pm 7.89$ ns \\
\hline Sham DCM extract & $252.00 \pm 6.11^{\mathrm{ns}}$ & $300.00 \pm 6.99^{\mathrm{ns}}$ & $278.00 \pm 7.13^{\mathrm{ns}}$ & $252.83 \pm 5.47^{\mathrm{ns}}$ & $228.74 \pm 7.99^{\mathrm{ns}}$ \\
\hline
\end{tabular}

\section{Discussion}

According to previously cited literature, M.charantia was investigated for its antithrombocytopenic effect but the proper scientific evaluation was not done. To date, no such studies reported for metabolic characterization of $M$. charantia and its action mechanism either clinically or preclinically. Keeping in mind, we strive to generate scientific data regarding its antithrombocytopenic efficacy and also enabled the bioactive metabolites using UPLC-MS.
Thrombocytopenia was successfully developed in Wistar rats by administration of busulfan induced. Moreover, the efficacy of DCM and mother extract of $M$. charantia was evaluated on busulfan-induced thrombocytopenic rats models. The present investigation suggested that DCM fraction impressively enhance platelets counts as compared to other fraction.

Interestingly, DCM fraction and mother extract possess significant effect $(p<0.05)$ against busulfan-induced groups and ameliorated the 
hematological parameters like a platelet, total lymphocyte, neutrophil count, leukocyte, hemoglobin, RBC, MCH, PCV/HCT, MCV, and MCHC. Restoration of the above-mentioned parameters was found more impressive in the case of the DCM fraction of M. charantia.

Presented results disclosed that some of the bioactive metabolites present in $M$. charantia can improve the hematological parameters in busulfan-induced thrombocytopenic rats. Bioactive metabolites, available in the fruits of $M$. charantia, avert the destruction of platelet in blood and ultimately improve the life of platelet in blood circulation. On the basis of the current studies, it can be concluded that $M$. charantia might be a promising platelet improving remedy or antithrombocytopenic agent. Cited literature reported that $M$. charantia alcoholic extract possesses an inhibitory effect on DENV-1.

Thrombocytopenia is a common clinical manifestation in which the PC counts were dropped from normal counts $(<40,000$ platelets $/ \mu l)$ and might be reached to lower than $<40,000$ platelets $\mu$ l of the blood sample (Ahmad et al., 2019). Both DCM fraction and mother extracts of $M$. charantia fruits showed excellent efficacy against viral infection, and these fractions and extracts were capable to reverse the blood count near to normal (Machado et al., 2018). Earlier studies reported that, M. charantia enhanced PC in the rat (Arollado, 2013).

M. charantia has been extensively utilized in traditional medicine to improve thrombocyte count in dengue viral infection (Anon, 2013). Physiologically, cytokine modulates the production of thrombocyte levels. Therefore, a diminished level of cytokine may reduce platelet production and might lead to the thrombocytopenic condition. Some bioactive compounds stimulate the production of cytokine, and this biological exploration of thrombopoietin justifies the traditional medicinal claims for the pharmacological action of $M$. charantiain thrombocytopenia.

UPLC-MS qualitative analysis of different extracts and fractions indicate that $M$. charantia is enriched with bioactive metabolites. Most of the metabolites identified in the extract or fraction are responsible for pharmacological activities. Chromatographic studies are one of the prime approaches to evaluate the quality of herbal formulation or food supplements. In the current present study, UPLCMS was performed to identify and authenticate the fraction and extract of $M$. charantia fruits to establish the quality. Bioactive metabolites present in the plant having good antioxidant potential, especially polyphenols, are capable to improve platelet production (Djati, 2017). Our study and cited literature suggested that $M$. charantia potentially increases PC level (Blache and Bontoux, 1988). The presence of many bioactive metabolites strongly supports the traditional system of medicine claimed by healers about $M$. charantia. Based on the present finding, $M$. charantia excellently improves the antithrombocytopenic activity in a busulfan-induced thrombocytopenic rat model.

\section{Conclusion}

The standardized mother extract of $M$. charantia and its DCM fraction significantly ameliorates PC in thrombocytopenic rats. This is the first study that highlights the antithrombocytopenic potential of $M$. charantia scientifically. Hence, extensive work is required to identify the responsible bioactive compounds in $M$. charantia for the antithrombocytopenic activity.

\section{Acknowledgments}

The authors are grateful to BNPL, SPER, Jamia Hamdard for laboratory assistance. The authors are very thankful to Dr. Rabea Parveen for her support in the improvement of the manuscript.

\section{Conflict of interest}

The authors declare no conflicts of interest relevant to this article.

\section{References}

Abdul Kadir, S.L.; Yaakob, H. and Zulkifli, R.M. (2013). Potential antidengue medicinal plants: A review. J. Nat. Med., 67(4):677-689.

Ahmad, A.; Ibrahim, M.; Chester, K.; Khan, W.; Ahmad, S. and Ansari, S.H. (2019). Antithrombocytopenic potential of bioactivity guided fractions of traditionally used Psidium guajava Linn. leaves in busulfan inducedthrombocytopenic rats. Pharmacog. Mag., 15(66):440.

Arollado, E. C. (2014). Platelet augmentation activity of selected Philippine plants. Int. J. Pharm. Phytopharmacological Res., 3(2):121-123.

Beloin, N.; Gbeassor, M.; Akpagana, K.; Hudson, J.; de Soussa, K.; Koumaglo, K. and Arnason, J.T. (2005). Ethnomedicinal uses of Momordica charantia (Cucurbitaceae) in Togo and relation to its phytochemistry and biological activity. J. Ethnopharmacol, 96(1-2):49-55.

Blache, D.and Bontoux, G. (1988). Biological effects of oxysterols on platelet function. Thromb. Res., 50(1):221-230.

Colli, A.; Gana, J.C.; Yap, J.; Adams Webber, T.; Rashkovan, N.; Ling, S.C. and Casazza, G. (2017). Platelet count, spleen length, and platelet count to spleen length ratio for the diagnosis of oesophagealvarices in people with chronic liver disease or portal vein thrombosis. Cochrane Database Syst. Rev., 4(4):1-155.

Costa, J.G.M.;Nascimento, E.M.; Campos, A.R. and Rodrigues, F.F. (2010), Antibacterial activity of Momordica charantia (Curcubitaceae) extracts and fractions. Journal of Basic and Clinical Pharmacy, 2(1): 45-51.

Dar, U.K.; Owais, F.; Ahmad, M. and Rizwani, G.H. (2014). Biochemical analysis of the crude extract of Momordica charantia (L.). Pak. J. Pharm. Sci., 27(6):2237-2240.

Dhurat, R. and Sukesh, M.S. (2014). Principles and methods of preparation of platelet-rich plasma: A review and author's perspective. Journal of Cutaneous and Aesthetic Surgery, 7(4):189-197.

Djati, M.S.; Habibu, H.; Jatiatmaja, N.A. and Rifai, M. (2017). Tapakliman (Elephantopus scaber L) extract-induced CD4+ and CD8+ differentiation from hematopoietic stem cells and progenitor cell proliferation in mice (Musmus culus L). In AIP Conference Proceedings, 1908(1):060003-9.

Fernandes, N.P.;Lagishetty, C.V., Panda, V.S. and Naik, S.R. (2007). An experimental evaluation of the antidiabetic and antilipidemic properties of a standardized Momordica charantia fruit extract. BMC Complement Altern. Med., 7(1):1-8.

Grover, J.K. and Yadav, S.P. (2004). Pharmacological actions and potential uses of Momordica charantia: A review. J. Ethnopharmacol., 93(1): $123-132$.

Habicht, S.D.; Kind, V.; Rudloff, S.; Borsch, C.; Mueller, A.S.;Pallauf, J. and Krawinkel, M.B. (2011). Quantification of antidiabetic extracts and compounds in bitter gourd varieties. Food Chem, 126(1):172-176.

Huang, W.C.; Tsai, T.H.; Huang, C.J.; Li, Y.Y.; Chyuan, J.H.; Chuang, L.T. and Tsai, P.J. (2015). Inhibitory effects of wild bitter melon leaf extract on Propioni bacterium acnes-induced skin inflammation in mice and cytokine production in vitro. Food Funct., 6(8):2550-2560. 
Ibrahim, M.; Parveen, B.; Zahiruddin, S.; Gautam, G; Parveen, R.; Khan, M.A.and Ahmad, S. (2021). Analysis of polyphenols in Aegle marmelos leaf and ameliorative efficacy against diabetic mice through restoration of antioxidant and anti-inflammatory status. J. Food Biochem., 46(10):1-15.

Jagessar, R.C.; Mohamed, A. and Gomes, G. (2008). An evaluation of the antibacterial and antifungal activity of leaf extracts of Momordica charantia against Candida albicans, Staphylococcus aureus and Escherichia coli. Nat. Sci., 6(1):1-14.

Jia, S.; Shen, M.; Zhang, F.andXie, J. (2017). Recent advances in Momordica charantia: Functional components and biological activities. Int. J. Mol. Sci., 18(12):25-55.

Kickler, N.; Lacombe, E.;Chassain, C.; Durif, F.; Krainik,A.;Farion, R. and Savasta, M. (2009). Assessment of metabolic changes in the striatum of a rat model of parkinsonism: An in vivo 1H MRS study. NMR Biomed, 22(2):207-212.

Lee, S.and Lee, D.K. (2018). What is the proper way to apply the multiple comparison test. Korean J. Anesthesiol., 71(5):353.

Lee-Huang, S.; Huang, P.L.; Nara, P.L.; Chen, H.C.; Kung, H.F., Huang, P. and Huang P.L. (1990). MAP 30: A new inhibitor of HIV-1 infection and replication. FEBS Letters, 272(1-2):12-18.

Lucas, E.A.; Dumancas, G.G.; Smith, B.J.; Clarke, S.L. and Arjmandi, B.H. (2010) Health benefits of bitter melon (Momordica charantia). Bioactive Foods in Promoting Health, 35(1):525-549.

Machado, A.J.; Santos, A.T.; Martins, G.M.; Cruz, R.P.; Costa, M.D.S.; Campina, F.F.and Morais-Braga, M.F. (2018). Antiparasitic effect of the Psidium guajava L.(guava) and Psidium brownianum MART. EX DC. (araçáde-veado) extracts. Food Chem. Toxicol., 119(3):275-280.

Mada, S.B.; Garba, A.; Mohammed, H.A.; Muhammad, A.; Olagunju, A. and Muhammad, A.B. (2013). Antimicrobial activity and phytochemical screening of aqueous and ethanol extracts of Momordica charantia L. leaves. J. Med. Plant Res., 7(10):579-586.
Periayah, M.H.; Halim, A.S. and Saad, A.Z.M. (2017). Mechanism action of platelets and crucial blood coagulation pathways in hemostasis. Int. J. Hematol. Oncol. Stem Cell Res., 11(4):319.

Pisoschi,A.M.; Pop,A.; Cimpeanu, C. and Predoi, G. (2016). Antioxidant capacity determination in plants and plant-derived products: A review. Oxid. Med. Cell. Longev., 9130976:1-36.

Prasad, V.; Jain, V.; Girish, D. and Dorle, A.K. (2006). Wound-healing property of Momordica charantia L. fruit powder. J. Herb. Pharmacother., 6(3-4):105-115.

Raman, A. and Lau, C. (1996). Antidiabetic properties and phytochemistry of Momordica charantia L.(Cucurbitaceae). Phytomedicine, 2(4): 349-362.

Ullah, M.; Showkat, M.; Ahmed, N.U.; Islam, S. and Absar, N. (2012). Evaluation of Momordica charantia L. fruit extract for analgesic and antiinflammatory activities using in vivo assay. Res. J. Med. Plant, 6(3): 236-244.

Venkataraman, N.; Pamukuntla, S.; Banoth, J.; Boini, P. and Sampathi, S. (2015). Platelet augmentation activity of Andrographis paniculata extract and andrographolide against cyclophosphamide induced thrombocytopenia in rats. Pharm. Pharmacol. Int. J., 2(4):00029.

Virdi, J.; Sivakami, S.; Shahani, S.; Suthar, A.C.; Banavalikar, M.M. and Biyani, M.K. (2003). Antihyperglycemic effects of three extracts from Momordica charantia. J. Ethnopharmacol., 88(1):107-111.

Wada, A.; Takagi, Y.; Kono, M. and Morikawa, T. (2015). Accuracy of a new platelet count system (PLT-F) depends on the staining property of its reagents. PLoS One, 10(10):1-13.

Zunjar, V.; Dash, R.P.; Jivrajani, M. Trivedi, B. and Nivsarkar, M. (2016). Antithrombocytopenic activity of carpaine and alkaloidal extract of Carica papaya Linn. leaves in busulfan induced thrombocytopenic Wistar rats. J. Ethnopharmacol., 181(16):20-25. 